\title{
Iatrogenic Damage to the Periodontium Caused by Implants and Implant Treatment Procedures
}

\author{
Syed Sirajuddin ${ }^{1, *}$, Krishna Kripal ${ }^{1}$, Kumuda $\mathrm{MN}^{1}$, Sachidananda Chungkham ${ }^{1}$, Syed Rafiuddin ${ }^{2}$ \\ and Chandrashekar BM ${ }^{1}$
}

\author{
${ }^{I}$ Department of Periodontology, Rajarajeswari Dental College \& Hospital, Bangalore-560074. Karnataka, India; \\ ${ }^{2}$ Department of Orthodontics, Sri Hasanamba Dental College and Hospital, Hassan ,Karnataka, India
}

\begin{abstract}
A dental implant (also known as an endosseous implant or fixture) is a surgical component that interfaces with the bone of the jaw or skull to support a dental prosthesis such as a crown, bridge, denture, facial prosthesis or to act as an orthodontic anchor.Well planned, comprehensive treatment plans lead to successful implant treatment and patient satisfaction, which are the eventual long-term objectives. Probability of implant success can be put at jeopardy by absolute and relative risk factors.
\end{abstract}

Keywords: Crown, iatrogenic damage, implant, implantitis, periodontium.

\section{INTRODUCTION}

An alternate treatment for replacing a missing tooth is a dental implant. An implant is a titanium screw that is placed in the area of the missing tooth.

The implant stabilizes and becomes a prosthetic root as the bone around the implant heals and "integrates" into the threads of the screw. Three months afterthe placement of the new root, a series of molds are created of the implant. A crown is then made and cemented to the new root, restoring full esthetics and function to the area. Majority of implant cases are successful leading to the most expected result in dentistry today.

During implant placement surgical complications are very common. According to a retrospective study by McDermott et al. 677 patients (2379 implants) were examined, and an overall frequency of complications was $13.9 \%$ [1]. Inflammatory and prosthetic complications were $10.2 \%$ and $2.7 \%$, respectively whereas operative complications made up a mere $1 \%$. Complications are anticipated and can lead to poor treatment outcomes.

\section{PERI-IMPLANT MUCOSITIS}

The clinical features of peri-implant mucositis (Figs. 1, 2) are in many respects similar to those of in gingivitis at teeth and include classical symptoms of inflammation, such as swelling and redness. Bleeding on probing $(\mathrm{BoP})$ is a good discriminating indicator of peri- implant mucositis. The prevalenceof this disease remains difficult to estimate since data on $\mathrm{BoP}$ at implants are infrequently reported [2]. In a study on 25 subjects treatedwith implant-supported fixed

*Address correspondence to this author at the Department of Periodontology, Rajarajeswari Dental College and Hospital, Mysore road, Bangalore560074, Karnataka, India; Tel: 09845904048;

E-mail:sirrushah@yahoo.co.in prosthesis, Lekholm et al. reported that bleeding on probingoccurred at $80 \%$ of theimplants [3]. Roos-Jansaker et al. examined 987 implants in 216 patients and reported that more than $73 \%$ of all implants exhibitedbleeding on probing [4]. Higher frequenciesof bleeding on probing at implants were presented by Franssonet al. in a study on 82 subjects. It was reported that bleeding on probingoccurred in more than $90 \%$ ofimplant sites [5].

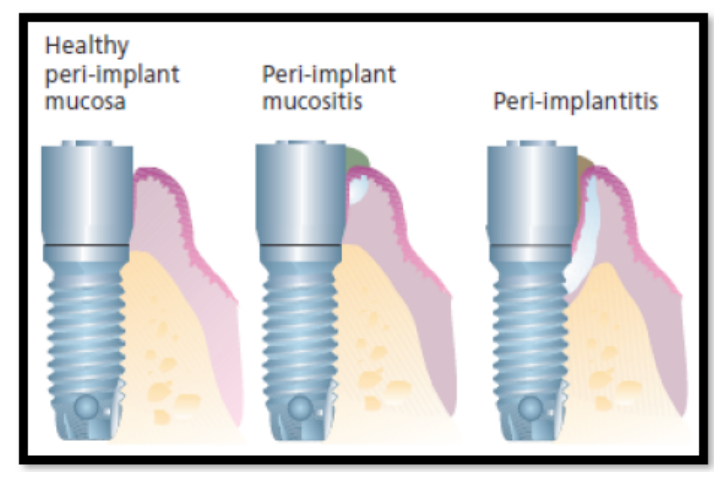

Fig. (1). Schematic drawing illustrating healthy peri-implant mucosa, peri-implant mucositis, and peri-implantitis.
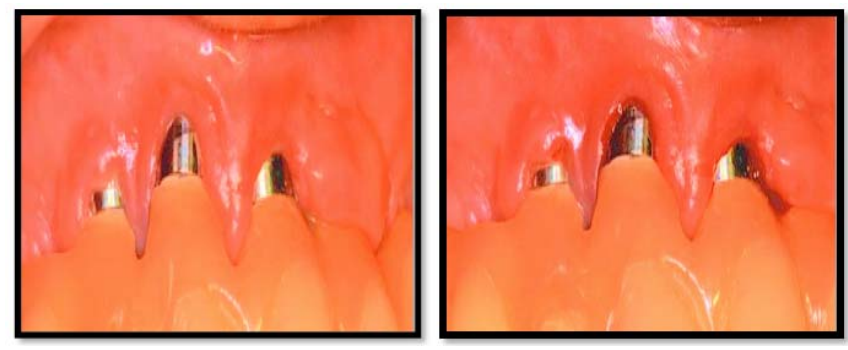

Fig. (2). Clinical symptoms of peri-implant mucositis including varying signs of redness and swelling. (b) Probing resulted in bleeding from the margin of the mucosa. 


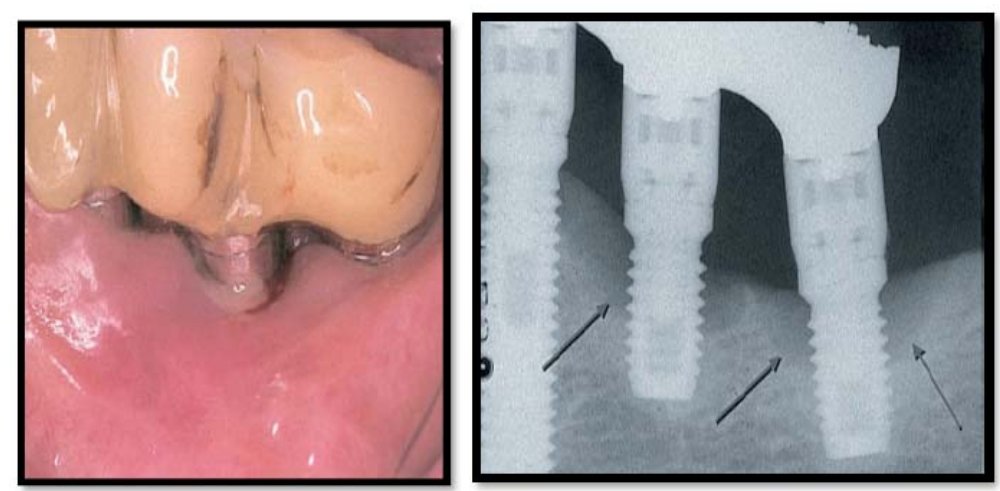

Fig. (3). Clinical (a) and radiographic (b) characteristics of two implant sites with peri- implantitis in the left side of the mandible. Note the presence of swelling and suppuration in the peri-implant mucosa (a) and the crater-formed bone destruction around the implants in the radiograph (arrows) (b). Peri-implantitis lesions are poorly encapsulated, extend to the marginal bone tissue and may, if they are allowed to progress, lead to the loss of the implant.

Zitzmannetal [6] studied the response toplaque formation in the soft tissues at implant andtooth sites in humans. Twelve subjects with healthy periodontal and peri-implant conditions were asked to refrain from tooth/implant cleaning for a period of 3 weeks. Clinical examinations were performed and soft tissue biopsies were harvested prior to andat the completion of the plaque accumulation period. Thetissues were examined using histologic techniques.

It was established that plaque buildup was related with clinical signs of soft tissue inflammation.

Furthermore, the initially minutelesions in the gingiva and in the peri-implant mucosa markedly increased in size after 3 weeks of plaque build-up: from $0.03 \mathrm{~mm} 2$ at baseline to $0.3 \mathrm{~mm} 2$ (gingiva) and $0.2 \mathrm{~mm} 2$ (peri-implant mucosa). In addition, the proportion of $\mathrm{B}$ cells and neutrophils increased more in the lesion in the gingiva than in its counterpart in the peri-implant mucosa.

\section{PERI-IMPLANTITIS}

Peri-implantitis represents a clinical condition that includes the presence of an inflammatory lesion in the periimplant mucosa and loss of peri-implant bone. The assessment of the diagnosis peri-implantitis must consequently require detection of both bleeding on probing (BoP) as well as bone loss in radiographs. Peri-implantitis initially affects the marginal part of the peri-implant tissues and the implant may remain stable and in function for varyingperiods of time. Implant mobility is therefore not an essential symptom for peri-implantitis but may occur in a final stage of disease progression and indicates complete loss of integration. Symptoms of peri-implantitis relate to the infectious inflammatory nature of the lesion. Thus, there is radiographic evidence of bone loss and the bone loss often has the shape of a crater. Swelling and redness of the mucosa as well as bleeding on gentle probing occur. Suppuration is also a frequent finding. The implant may remain stable over long periods.If left untreated, however, peri-implantitis may progress and lead to implant loss. Symptoms of peri-implantitis (Fig. 3) relate to the infectious inflammatory nature of the lesion. Thus, there is radiographic evidence of bone loss and the bone loss often has the shape of a crater. Swelling and redness of the mucosa as well as bleeding on gentle probing occur. Suppuration is also a frequent finding. The implant may remain stable over long periods.

The large numbers of neutrophils in the peri-implantitis lesion and the absence of an epithelial lining between the lesion and the biofilm, indicate that the peri-implantitis lesions have features that are different from those of periodontitis lesions. Progression of peri-implantitis is more pronounced at implants with rough surfaces than smooth surfaces.

\section{CONCLUSION}

Most of the factors that lead to implant failure can be controlled by the dentist by means of proper treatment planning.Surgical implant complications are common and should be managed immediately. Surgical implant complications may be iatrogenic, due to poor treatment techniques, or lack of understanding between dental disciplines. Adequate treatment plan must be accomplished in the implant "planning" stages, such as tracing preoperative radiographs, measuring models, taking CT scans and making proper surgical guides. Basic anatomy must not be forgotten and should be reviewed by the surgeon in every case.

\section{CONFLICT OF INTEREST}

The authors confirm that this article content has no conflict of interest.

\section{ACKNOWLEDGEMENTS}

Declared none.

\section{REFERENCES}

[1] McDermott N, Chuang S, Dodson T, et al. Complications of dental implants: Identification, frequency, and associatedrisk factors. Int $\mathrm{J}$ Oral Maxillofac Implants 2003; 18: 848-55.

[2] Berglundh T, Persson L, Klinge B. A systematic review on the incidence of biological and technical complications in implant dentistry reported in prospective longitudinal studies of at least 5 years. Proceedings from the $4^{\text {th }}$ European Workshop on Periodontology. J Clin Periodontol 2002; 29: 197-212. 
[3] Lekholm U, Adell R, Lindhe J, et al. Marginal tissue reactions at osseointegrated titanium fixtures. (II) A cross-sectional retrospective study. Int J Oral Maxillofac Implants 1986; 15: 53-61.

[4] Roos-Jansåker AM, Lindahl C, Renvert H, Renvert S. Nine- to fourteen-year follow-up of implant treatment. Part I: implant loss and associations to various factors. J Clin Periodontol 2006; 33: 283-9.
[5] Fransson C, Lekholm U, Jemt T, Berglundh T. Prevalence of subjects with progressive loss at implants. Clin Oral Implants Res 2005; 16: 440-6.

[6] Zitzmann NU, Berglundh T, Ericsson I, Lindhe J. Spontaneous progression of experimentally induced peri-implantitis. J Clin Periodontol 2004; 31: 845-9.

Received: December 22, 2014

Revised: March 04, 2015

Accepted: March 10, 2015

(c) Sirajuddin et al.; Licensee Bentham Open.

This is an open access article licensed under the terms of the Creative Commons Attribution Non-Commercial License (http://creativecommons.org/licenses/by-nc/3.0/) which permits unrestricted, non-commercial use, distribution and reproduction in any medium, provided the work is properly cited. 